\title{
QUALITY OF LIFE AND ITS CORRELATES IN STUDENTS OF A UNIVERSITY OF THE THIRD AGE
}

\author{
EWA NIEDZIELSKAㄴ, MONIKA GUSZKOWSKA², EWA KOZDROŃ¹, ANNA LEŚ3, \\ BARTŁOMIEJ KRYNICKIㄴ, JOANNA PIOTROWSKA ${ }^{1}$
}

Józef Piłsudski University of Physical Education in Warsaw, Faculty of Tourism and Recreation, Chair of Recreation, Department of Recreation Methodologyl, Department of Recreation Theory ${ }^{3}$, Faculty of Rehabilitation, Chair of Psychosocial Aspects of Health and Rehabilitation, Department of Clinical Psychology and Special Education ${ }^{2}$

\author{
Mailing address: Ewa Niedzielska, Józef Piłsudski University of Physical Education, Department of Recreation \\ Methodology, 34 Marymoncka Street, 00-986 Warsaw, tel.: +48 22 8340431, fax: +48 22 8651080, \\ e-mail: ewaniedzielska38@gmail.com
}

\begin{abstract}
Introduction. The aim of the study was to determine the quality of life of students of a University of the Third Age (U3A) and examine its correlations with demographic variables, physical fitness, perception ability, and emotional well-being. Material and methods. The study involved 116 women aged 50 to 88 years who participated in U3A classes held at the University of Physical Education in Warsaw. Quality of life was assessed using an abridged version of the WHOQOL-BREF questionnaire. Additionally the Fullerton Functional Fitness Test, a dynamometer hand grip strength test, and Romberg's test were performed. The Attention and Perceptiveness Test (version 6/9) by Ciechanowicz and Stańczak, the UMACL Mood Adjective Checklist by Matthews, Chamberlain, and Jones, as well as the Geriatric Depression Scale by Yesavage were also used. Finally, data concerning age, marital status, economic status, chronic diseases, and medication use was collected with a specially designed questionnaire. Results. The U3A students who took part in the study perceived their quality of life as relatively high. The domain of quality of life which was found to be the most strongly correlated with demographic variables was the psychological health domain: scores in this domain decreased with the subjects' age and increased with their level of education and economic status. Health satisfaction was directly proportional to economic status and inversely proportional to the level of education. Depression scores correlated significantly negatively with quality of life scores in all domains, the overall perception of quality of life, and health satisfaction, as well as predicting quality of life in the domains of psychological health and the environment. The predictors of the subjects' perceived quality of life were the following: lower body strength, agility, flexibility, and aerobic endurance. Conclusions. The findings of the study confirm that demographic variables (age, education, and economic status), depression and mood, as well as physical fitness are important predictors of quality of life in women in late adulthood.
\end{abstract}

Key words: quality of life, older adults, physical fitness, perception ability, mood, depression

\section{Introduction}

With increasing life expectancy and declining birth rates, persons aged over 65 years are now the fastest growing age group in industrialised countries, where they constitute an increasing proportion of the population. In this situation, making sure that this group maintains a satisfying level of cognitive and physical ability as well as emotional well-being - and, as a result, a satisfying quality of life - is becoming a major challenge for society.

The concept of quality of life is multidimensional, and it is related to a person's physical and emotional well-being as well their economic status, social status, and satisfaction of feeling productive [1]. From the psychological perspective, quality of life is related to an individual's sense of satisfaction, well-being, and happiness understood in a broad sense [2]. A given person's quality of life is determined based on their subjective evaluation of their life in general or of its dimensions. The determinants of quality of life in older adults include their physical, emotional, intellectual, and social functioning, life satisfaction, health satisfaction, economic status, vitality, energy, and leisure time activities.
Health is one of the key factors impacting quality of life [3]. The relationship between health and quality of life has been confirmed in research involving older adults in health-threatening conditions [4], in long-term care [5], after stroke [6], and with coronary artery disease [7]. Moreover, patients aged over 65 years have been found to assess their quality of life as higher after leaving the hospital [8].

As already mentioned, apart from being influenced by health, quality of life is also determined by demographic variables, such as age, gender, education, and place of residence $[9$, 10, 11]. Wysokiński et al. [4] have concluded that perceived quality of life correlates negatively with age and positively with the level of education. Similar conclusions were drawn by Fidecki et al. [5] and Kowalska et al. [12]. In addition, age was proven to be a significant negative predictor of quality of life in women in late adulthood [13, 14].

However, not all research investigating the relationship between quality of life and demographic variables has confirmed that such correlations exist. In a study by Grzanka-Tykwińska et al. [15], gender, age, education, economic status, and place of residence did not have a significant impact on the quality of 
life of patients aged over 60 years. Pacian et al. [16] also did not observe statistically significant correlations between particular domains of quality of life and demographic variables.

In women, quality of life additionally negatively correlates with the symptoms of menopause [17]. Janicka [18] conducted a study comparing the quality of life of women in middle and late adulthood, where the determinant of perceived quality of life was hormonal changes due to menopause. Symptoms related to this process were found to have a significant impact on the women's perception of their quality of life $[19,20]$.

As far as emotional variables which change over time are concerned, factors such as mood, and especially the risk of depression, can have a considerable impact on perceived quality of life [17]. This has been confirmed, among others, in a study involving outpatients of a geriatric clinic and residents of a nursing home in Bydgoszcz, Poland [21]. In this study, the emotional state of the subjects was observed to have a significant influence on their perception of their quality of life in all of its aspects (physical health, psychological health, social relationships, and the environment). The higher the depression scores were, the lower the subjects' quality of life was.

Quality of life is, therefore, strongly correlated with emotional well-being and life satisfaction [22]. These, in turn, are related to physical activity.

Research has sought direct correlations between physical activity and quality of life in late adulthood. According to Rejeski and Mihalko [23], there is empirical evidence, including from experimental research, which proves that such correlations exist. For example, a six-week exercise programme was found to increase perceived quality of life in post-menopausal women [24].

Correlative studies have also confirmed the existence of such relationships. A study involving persons aged over 65 years showed that physical, intellectual, and social activity correlated with health and quality of life [25]. Active persons were hospitalised less frequently and were healthier and fitter. The precondition for having a higher quality of life was maintaining satisfactory physical and intellectual ability as well as social relationships [26].

The results of research suggest that physical activity performed earlier in life also plays an important role. Spending leisure time in an active way in one's youth has been shown to influence functional fitness in older age. Persons who were active when they were young regarded their health condition as better and functioned better in everyday life when they were older [27].

In our previous research [28], we compared life satisfaction in three groups of women aged 65 to 90 years: physically active women (who participated in physical activity classes for persons aged over 50 years three times a week), socially active women (who took part in activities for older adults organised by a cultural community centre), and inactive women. Women who were physically and socially inactive differed significantly from the other two groups, in that they were less satisfied with their lives, had lower mood, and experienced greater mental health issues. This means their psychological well-being was worse than that of the other women. Moreover, the results obtained by the active women in the two groups were similar, which led us to conclude that the psychological well-being of older women correlated positively with their activity, regardless of its nature.

The second part of our previous study [28] involved women aged 58 to 81 years, including: physically active women (systematically participating in physical activity classes for older adults), female students of a University of the Third Age (U3A) who engaged both in physical and cognitive activity, and women who were neither cognitively nor physically active. The latter group was observed to be significantly less satisfied with life, have a lower sense of life meaning, and have a lower sense of coherence. Physically active women were characterised by the strongest sense of comprehensibility, while U3A students had the strongest sense of manageability and meaningfulness.

The results of our previous research [28] have proven that there is a relationship between physical activity and quality of life in women in late adulthood. Physically active women were characterised by greater life satisfaction, a higher sense of life meaning, and fewer psychological issues than inactive women. The level of their psychological well-being was similar to that of women who were socially and intellectually active. This would again suggest that in order to maintain a high quality of life in late adulthood, one needs to be active, but the nature of this activity does not play a major role.

It is known that there is a positive correlation between physical fitness and quality of life in persons in late adulthood. However, the question of whether cognitive ability, including perception ability, has a similar impact on quality of life has not been investigated as thoroughly by researchers. In light of the current state of research, the aim of the study was to determine the quality of life of students of a University of the Third Age and explore their correlations with demographic variables, physical fitness, perception ability, and emotional well-being.

\section{Material and methods}

The study involved 116 women aged 50 to 88 years $(\mathrm{M}=$ 68.17; $\mathrm{SD}=6.395$ ) who participated in University of the Third Age classes held at the University of Physical Education in Warsaw. The majority of the subjects had higher education (58.8\%), whereas most of the remaining women had secondary education $(40.0 \%)$, and only $1.3 \%$ had primary education. Most of the subjects (46.8\%) were married, $29.9 \%$ were widows, $16.9 \%$ were divorced, and $6.5 \%$ were unmarried. Nearly half of them (45.6\%) lived alone, a similar number lived with their husbands (44.2\%), and every tenth subject (10.4\%) lived with other family members. The women most frequently regarded their economic status as average (39.0\%) and good (37.7\%) and less often as very good and bad (10.4\%); only $2.6 \%$ saw it as very bad. Twothirds of the subjects (67.1\%) suffered from chronic disease, and $83.1 \%$ took medication regularly.

Quality of life was assessed using an abridged version of the WHOQOL-BREF questionnaire. WHOQOL is an instrument designed for assessing quality of life in healthy and unhealthy persons, both for research and treatment purposes. It makes it possible to obtain a profile of quality of life in the four following domains: physical health, psychological health, social relationships, and the environment. It also contains questions which are analysed separately: the first question regarding the individual's overall perception of their quality of life and the second question regarding their overall perception of their health (which will be referred to as health satisfaction in the current article). The number of points for the domains mentioned above reflects the respondent's perception of quality of life related to a given domain; the higher the score is, the better their perceived quality of life is.

In order to determine the respondents' level of physical fitness, the Fullerton Functional Fitness Test was performed, which consists of the following six tests carried out consecutively: 
1) Arm Curl Test, testing the muscular endurance of the upper body;

2) 30-second Chair Stand Test, testing the strength of the lower body;

3) Back Scratch Test, testing the flexibility of the upper body;

4) Chair Sit and Reach Test, testing the flexibility of the lower body, in particular of the hamstring tendons;

5) 8-Foot Up and Go Test and 6-Minute Walk Test, testing agility (dynamic balance) and aerobic endurance;

6) 2-Minute Step in Place Test, testing aerobic endurance, which is performed when it is impossible for the subject to do the 6-Minute Walk Test.

Also hand grip strength test using a dynamometer was measured and static balance by carrying out Romberg's test with the eyes open and closed was assessed. Moreover, the number of U3A physical activity classes the subjects participated in was recorded.

Perception ability was evaluated using the Attention and Perceptiveness Test (version 6/9) by Ciechanowicz and Stańczak [29], which measures perception speed (number of symbols examined), perception failure (number of symbols crossed out erroneously), and attention failure (number of symbols ignored). A standard testing time of 3 minutes was used.

Mood was assessed using the Polish adaptation of the UMACL Mood Adjective Checklist by Matthews, Chamberlain, and Jones developed by Goryńska [30], which consists of 29 items that form three scales: tense arousal, 9 items; energetic arousal, 10 items; and hedonic tone, 10 items. Tense arousal is associated with fearfulness; persons who score high on this scale are tense and stressed. Energetic arousal is related to the feeling that one has the energy to perform action, so it has a mobilising effect; those with high scores on this scale feel energetic, active, and ready for action. Hedonic tone refers to subjective feelings of pleasantness and unpleasantness; those who score high on this scale feel strong positive emotions.

Depressive symptoms were measured using the Geriatric Depression Scale by Yesavage (in a 15-point version) [31]. The scale consists of 15 questions describing the basic symptoms of depression, and the respondent is to confirm or deny that they have had the symptoms in the past two weeks by answering "yes" or "no". It is assumed that a score from 11 to 15 points indicates severe depression, and one of 6 to 10 points proves that the person is moderately depressed.

Finally, the data concerning age, marital status, economic status, chronic diseases, and medication use was collected by means of a specially designed questionnaire.

\section{Results}

Table 1 shows the descriptive statistics for the results of the WHOQOL questionnaire, that is the answers to the first two questions and the mean scores in the four domains. Each score can range from 1 to 5 . In order to compare the scores for perceived quality of life in particular domains, the Friedman test was used, whose result (chi square $=28.100 ; \mathrm{p}<0.001$ ) indicated that there were significant differences between the quality of life scores in particular domains. The results of the Wilcoxon matched pairs test showed that the score for the domain of social relationships was significantly different from the scores in other domains - psychological health $(Z=5.235$; $p<0.001)$, the environment $(Z=4.060 ; \mathrm{p}<0.001)$, and physical health $(Z=$ 3.446; $\mathrm{p}=0.001)$ - whereas other scores did not differ significantly (tab. 1).
Table 1. Quality of life of the students of the University of the Third Age

\begin{tabular}{|l|c|c|c|c|}
\hline \multicolumn{1}{|c|}{ Indicators of quality of life } & Min. & Max. & M & SD \\
\hline Overall perception of quality of life & 3 & 5 & 4.10 & 0.504 \\
\hline Health satisfaction & 1 & 5 & 3.61 & 0.720 \\
\hline Physical health & 2.71 & 4.86 & 3.83 & 0.439 \\
\hline Psychological health & 2.67 & 4.50 & 3.87 & 0.422 \\
\hline Social relationships & 2.33 & 5.00 & 3.67 & 0.526 \\
\hline Environment & 2.25 & 4.88 & 3.87 & 0.466 \\
\hline
\end{tabular}

In order to determine the relationships between perceived quality of life and the variables included in the study, we calculated Pearson product-moment correlation coefficients. The domain which was found to be most strongly correlated with demographic variables was psychological health: it dropped with the subjects' age and increased with their level of education and economic status. Health satisfaction was directly proportional to the subjects' economic status and inversely proportional to their education.

There were few correlations between perceived quality of life and physical fitness. Perceived quality of life in the psychological health domain correlated positively with balance and aerobic endurance, and that in the physical health domain correlated with agility. Quality of life in the environment domain correlated negatively with flexibility. The overall perception of quality of life, on the other hand, was found to have a positive correlation with the strength of the lower body, while health satisfaction correlated positively with the flexibility of the upper body (tab. 2).

Perception ability (perception failure and speed) correlated positively with perceived quality of life in the domain of social relationships, and perception speed additionally correlated with quality of life in the physical health domain.

The greatest number of correlations was found for the scores in depression, which correlated negatively with all of the indicators of perceived quality of life. All of the mood indicators were associated with the overall perception of quality of life and quality of life in the psychological health domain; positive mood states correlated with quality of life in the physical health domain and energetic arousal with that in the social relationships domain.

The stepwise regression analysis were also performed so as to determine the predictors of perceived quality of life among the respondents. The following variables were entered into the equation: the demographic variables, the scores in the tests measuring physical fitness and perception ability, and the scores for affective states (depression and mood).

The overall perception of quality of life could be predicted based on hedonic tone with almost $17 \%$ and lower body strength with $7 \%$ of the variance explained. Demographic and affective variables were found to be insignificant. Therefore, higher perceived quality of life could be expected in persons who had higher scores in hedonic tone and whose lower body was stronger (tab. 3).

As for perceived quality of life in the physical health domain, chronic diseases predicted $11 \%$ of the variance. Agility and depression accounted for the variance to a much lesser extent. A high perceived quality of life in the domain of physical health was found in persons who did not suffer from chronic diseases or depression and were more agile; perception ability was not observed to have a considerable impact in this respect (tab. 4). 
Table 2. Correlations between quality of life and demographic variables, physical fitness, perception ability, and mood (Pearson product-moment correlation coefficients)

\begin{tabular}{|c|c|c|c|c|c|c|}
\hline & $\begin{array}{l}\text { Overall perception } \\
\text { of quality of life }\end{array}$ & $\begin{array}{c}\text { Health } \\
\text { satisfaction }\end{array}$ & $\begin{array}{l}\text { Physical } \\
\text { health }\end{array}$ & $\begin{array}{l}\text { Psychological } \\
\text { health }\end{array}$ & $\begin{array}{l}\text { Social } \\
\text { relationships }\end{array}$ & Environment \\
\hline Age & -0.146 & 0.090 & 0.055 & $-0.329^{* * *}$ & $-0.196^{*}$ & 0.100 \\
\hline Education & 0.065 & $-0.252^{\star *}$ & -0.061 & $0.243^{* *}$ & 0.103 & $0.227^{*}$ \\
\hline Economic status & $0.301^{* * *}$ & $0.291^{* *}$ & -0.024 & $0.176^{t}$ & 0.108 & 0.121 \\
\hline Strength of left hand & 0.111 & -0.084 & -0.061 & 0.119 & -0.024 & -0.002 \\
\hline Strength of right hand & 0.101 & -0.020 & 0.031 & 0.113 & 0.064 & -0.028 \\
\hline Balance (left leg, eyes open) & 0.027 & 0.103 & -0.120 & $0.194^{*}$ & 0.112 & -0.119 \\
\hline Balance (right leg, eyes open) & 0.026 & 0.035 & -0.073 & 0.097 & 0.005 & 0.011 \\
\hline Balance (left leg, eyes closed) & 0.111 & 0.079 & 0.031 & 0.040 & 0.164 & 0.007 \\
\hline Balance (right leg, eyes closed) & 0.087 & 0.008 & -0.056 & -0.062 & -0.142 & -0.102 \\
\hline Aerobic endurance & 0.117 & 0.072 & 0.015 & $0.206^{*}$ & -0.036 & 0.074 \\
\hline Flexibility of lower body & -0.084 & 0.098 & 0.038 & -0.064 & -0.104 & $-0.201^{*}$ \\
\hline Flexibility of upper body (left arm) & -0.027 & $0.173^{t}$ & 0.052 & -0.024 & 0.027 & -0.064 \\
\hline Flexibility of upper body (right arm) & -0.035 & 0.128 & 0.030 & -0.092 & -0.067 & -0.085 \\
\hline Strength of lower body & $0.280^{* *}$ & -0.037 & 0.004 & 0.112 & 0.108 & 0.041 \\
\hline Agility & -0.082 & 0.068 & $0.248^{*}$ & -0.131 & -0.065 & -0.027 \\
\hline Perception speed & 0.038 & 0.093 & $0.183^{t}$ & 0.122 & $0.187^{t}$ & 0.033 \\
\hline Perception failure & -0.055 & 0.021 & 0.045 & -0.134 & $0.212^{*}$ & -0.102 \\
\hline Attention failure & -0.054 & 0.008 & 0.006 & 0.040 & -0.125 & -0.064 \\
\hline Depression & $-0.297^{* *}$ & $-0.197^{*}$ & $-0.309^{* * *}$ & $-0.484^{* * *}$ & $-0.183^{*}$ & $-0.256^{* *}$ \\
\hline Hedonic tone & $0.412^{\star * *}$ & -0.027 & $0.179 t$ & $0.420^{* * *}$ & 0.121 & 0.100 \\
\hline Energetic arousal & $0.254^{* *}$ & -0.079 & $0.178^{\mathrm{t}}$ & $0.439 * * *$ & $0.174^{t}$ & 0.009 \\
\hline Tense arousal & $-0.301^{* * *}$ & -0.046 & -0.117 & $-0.299 * *$ & -0.132 & -0.029 \\
\hline
\end{tabular}

$\mathrm{t}=$ tendency level $(0.1>\mathrm{p}>0.05) ;{ }^{*}=\mathrm{p}<0.05 ;{ }^{* *}=\mathrm{p}<0.01 ;{ }^{* * *}=\mathrm{p}<0.001$.

Table 3. Predictors of the overall perception of quality of life in the U3A students (stepwise regression analysis)

\begin{tabular}{|c|c|c|c|}
\hline Group of variables & Predictor & Beta & Model (R2; F; $\mathbf{p})$ \\
\hline Physical fitness & $\begin{array}{c}\text { Strength of lower } \\
\text { body }\end{array}$ & 0.279 & $0.069 ; 8.508 ; 0.004$ \\
\hline Mood & Hedonic tone & 0.417 & $0.166 ; 23.510 .0 .001$ \\
\hline
\end{tabular}

Table 4. Predictors of quality of life in the physical health domain in the U3A students (stepwise regression analysis)

\begin{tabular}{|c|c|c|c|}
\hline Group of variables & Predictor & Beta & Model $\left(\mathbf{R}^{2} ; \mathbf{F} ; \mathbf{p}\right)$ \\
\hline $\begin{array}{c}\text { Demographic } \\
\text { variables }\end{array}$ & Chronic diseases & -0.364 & $0.114 ; 6.893 ; 0.012$ \\
\hline Physical fitness & Agility & 0.245 & $0.050 ; 6.247 ; 0.014$ \\
\hline Perception ability & None & & \\
\hline Mood & Depression & -0.284 & $0.072 ; 9.635 ; 0.002$ \\
\hline
\end{tabular}

The perception of quality of life in the psychological health domain was predicted best (about 30\% of the explained variance) by the scores in depression and energetic arousal. Moreover, quality of life was rated higher, the younger the respondents were. None of the indicators of physical fitness or perception ability were significant in predicting the variance in this domain (tab. 5).
Table 5. Predictors of quality of life in the psychological health domain in the U3A students (stepwise regression analysis)

\begin{tabular}{|c|c|c|c|}
\hline Group of variables & Predictor & Beta & Model $\left(\mathbf{R}^{2} ; \mathbf{F} ; \mathbf{p}\right)$ \\
\hline $\begin{array}{c}\text { Demographic } \\
\text { variables }\end{array}$ & Age & -0.329 & $0.088 ; 5.325 ; 0.026$ \\
\hline \multirow{2}{*}{ Mood } & Depression & -0.356 & \multirow{2}{*}{$0.285 ; 23.313 ; 0.001$} \\
\cline { 2 - 3 } & Energetic arousal & 0.288 & \\
\hline
\end{tabular}

As far as the domain of social relationships is concerned, only one predictor was identified in the current study, namely perception failure, which, surprisingly, was a positive predictor (persons who made more errors in the attention test perceived their quality of life as higher than those who made fewer errors). However, this factor explained only $3.5 \%$ of the variance in quality of life in this domain (tab. 6).

Table 6. Predictors of quality of life in the social relationships domain in the U3A students (stepwise regression analysis)

\begin{tabular}{|c|c|c|c|}
\hline Group of variables & Predictor & Beta & Model (R2; F; $\mathbf{p})$ \\
\hline Perception ability & Perception failure & 0.212 & $0.035 ; 4.464 ; 0.037$ \\
\hline
\end{tabular}


Finally, when it comes to quality of life in the domain of the environment, the negative - though weak - predictors of quality of life were flexibility and depression. Demographic variables and perception ability did not predict the scores in this domain (tab. 7).

Table 7. Predictors of quality of life in the environment domain in the U3A students (stepwise regression analysis)

\begin{tabular}{|c|c|c|c|}
\hline Group of variables & Predictor & Beta & Model $\left(\mathbf{R}^{2} ; \mathbf{F} ; \mathbf{p}\right)$ \\
\hline Physical fitness & Flexibility & -0.200 & $0.030 ; 4.131 ; 0.045$ \\
\hline Mood & Depression & -0.274 & $0.067 ; 8.939 ; 0.003$ \\
\hline
\end{tabular}

\section{Discussion}

According to the results of the study, the U3A students perceived their quality of life as relatively high. However, it was significantly lower in the domain of social relationships than in the other domains. The score in perceived quality of life in this domain was similar to that in health satisfaction, but significantly lower than that in the overall perception of quality of life. Perceived quality of life was slightly higher in the U3A students than that reported in older persons with health issues $[4,5,6$, $7,8]$. This can be assumed to at least partially result from the better health state of the respondents who participated in the current study, which, according to previous studies [3, 7, 32], is a factor that is associated with quality of life. In this study, health issues (chronic diseases) were a significant negative predictor of perceived quality of life in the physical health domain, but not in the other domains.

In light of the findings of previous studies, one of the important determinants of perceived quality of life is age $[4,5,9$, $10,11,12]$. This has been partially confirmed by our data. Age was found to have a significant negative correlation with perceived quality of life, though not in all the domains and only in the psychological health and social relationships domains. Moreover, we did not observe a significant correlation between age and the overall perception of quality of life or health satisfaction, a result which is in line with the findings of Pacian et al. [16] and Grzanka-Tykwińska et al. [15]. It may be presumed that the relationship between age and perceived quality of life in older adults differs depending on the domain.

Education correlated positively with perceived quality of life in the psychological health and environment domains, as was the case in the studies by Wysokiński et al. [4], Fidecki [5], Bryła [32], and Kowalska [12]. Interestingly, the correlation with health satisfaction was negative, which would suggest that persons who are better educated have higher expectations regarding their health, and for this reason, they are less satisfied with it. It is worth noting, however, that the level of education did not predict any of the indicators of quality of life.

Another variable which correlated with perceived quality of life and health satisfaction was economic status. Nevertheless, it correlated significantly only with perceived quality of life in the domain of psychological health and did not predict it. Similar results in this respect were obtained by Bryła et al. [32].

To sum up, general demographic variables were relatively weakly correlated with perceived quality of life in the U3A students. A lack of differences in perceived quality of life with regard to age, education, and economic status has also been observed in previous studies $[15,16]$.
Despite the low variance in the depression scores and the small percentage of subjects who obtained scores which proved they had depression (6\%), it is depression that correlated the most strongly with the subjects' quality of life. The score on the Geriatric Depression Scale had a significant negative correlation with the scores in perceived quality of life in all domains, the overall perception of quality of life, and health satisfaction, and it made it possible to predict the scores in perceived quality of life in the psychological health and environment domains, though to a small extent in the latter. These findings are in line with those reported by Humańska and Kędziora-Kornatowska [21], Pacian et al. [16], and Bryła et al. [32]. It is worth emphasising at this point that the relationships between depression and quality of life found in self-report studies could be due to the fact that depression does in fact cause a decrease in quality of life, but they might also be magnified owing to the selective and modifying influence of negative mood on cognitive processes. Persons who are depressed are prone to evaluate various aspects of reality, including the quality of their own lives, more harshly.

Fewer correlations were observed between mood and perceived quality of life, and they mainly concerned the psychological health domain and the overall perception of quality of life. As was the case with depression, these relationships might be partly related to the impact of mood on cognitive processes.

The study found few (relatively weak) correlations between physical fitness and perceived quality of life. Greater physical fitness was associated with higher perceived quality of life and was its positive predictor. The following components of physical fitness played a significant role: the strength of the lower body, agility, flexibility, and aerobic endurance. These aspects of physical fitness were associated with successful ageing in a study involving the Taiwanese [33], its indicators being independence in daily life as well as satisfying cognitive and social function.

The results of physical fitness tests made it possible to predict quality of life in the U3A students only to a small extent. The results obtained in our study can be compared against those reported in a study carried out by Sławińska et al. [34] involving 216 women living in the city of Wrocław aged 50-84 years. Our subjects' perceived quality of life was predicted by the strength of the lower body, whereas that of the women from Wrocław was predicted by the muscular endurance of the upper extremity. Perceived quality of life in the physical health domain could be estimated based on agility in our cohort and based on the muscular endurance of the upper body and flexibility in the Wrocław cohort. The predictors of perceived quality of life in the environment domain were flexibility in our study and the strength and the flexibility of the upper extremity in the Wrocław study. In the current study, none of the physical fitness tests predicted quality of life in the psychological health domain. In the Wrocław study [34], on the other hand, flexibility of the upper body was found to be a quality of life predictor. Neither study identified predictors of quality of life in the domain of social relationships which would be related to physical fitness. The discrepancies between the results of these two studies alone prove that it is necessary to further investigate the relationships between physical fitness and perceived quality of life in older adults.

The only (positive) predictor of quality of life in the domain of social relationships was perception failure; at the same time, this was the only domain where perception ability was significant. This surprising result is difficult to interpret, and further research is needed in order to establish whether this relationship exists. 
The findings of our study, which involved U3A students, confirm that demographic variables (age, education, and economic status), depression and mood, as well as physical fitness are indeed predictors of quality of life in women in late adulthood.

\section{Literature}

1. Baumann K. (2006). Quality of life in old age - theoretical discourse. Gerontologia Polska 14, 165-171. [in Polish]

2. Bańka A. (2005). Psychology of quality of life. Poznań: Stowarzyszenie Psychologia i Architektura. [in Polish]

3. Ratkowski W., Grabowska-Skorb P., Bzdawski M., Napierała M., Zukow W. (2013). Quality of life in the first decade of the retirement age among the physically active and inactive inhabitants of the Tri-city. Journal of Health Sciences 16, 37-56. DOI: article-bd37970d-13bc-417c-9ae0db3ec8dc985a. [in Polish]

4. Wysokiński M., Fidecki W., Adamiec R., Burian J. (2011). Quality of life of elderly patients in life-threatening conditions. Pielęgniarstwo XXI wieku 4, 17-22. DOI: articlefc6eb851-6de2-4f4e-8453-663854flbl05. [in Polish]

5. Fidecki W., Wrońska I., Kędziora-Kornatowska K., Wysokiński M., Kulina D., Wadas T. et al. (2015). Healthrelated quality of life in elderly people provided with longterm care. Gerontologia Polska 1, 24-28. [in Polish]

6. Tasiemski T., Knopczyńska A., Wilski M. (2010). Quality of life after stroke - pilot study. Gerontologia Polska 18, 128133. [in Polish]

7. Kózka M., Majda A., Kula A. (2013). Evaluation of life quality and health behaviors of patients with stable coronary artery disease in geriatric age. Problemy Pieleggniarstwa 21, 433442. DOI: article-295ceeel-73fb-4184-9e2d-2lbdfb850043. [in Polish]

8. Ostrzyżek A. (2010). Assessment of life quality in elderly people rehabilitated in a long-term care unit. Problemy $\mathrm{Hi}$ gieny i Epidemiologii 91, 659-666. [in Polish]

9. Muszalik M., Kędziora-Kornatowska K. (2006). Quality of life in the chronically ill elderly. Gerontologia Polska 14, 185189. [in Polish]

10. Bilotta C., Bowling A., Nicolini P. (2011). Older people's quality of life (OPQOL) scores and adverse health outcomes at a one-year follow-up. A prospective cohort study on older outpatients living in the community in Italy. Health and Quality of Life Outcomes 9, 72. DOI: 10.1186/1477-7525-972.

11. Miłkowska G. (2012). A sense of quality of life of seniors in selected European Union member countries. Prace Naukowe Akademii im. Jana Długosza w Częstochowie, Seria: Pedagogika 31, 235-251. [in Polish]

12. Kowalska M., Humeniuk M., Danso F., Kułak E., Arasiewicz H. (2011). Quality of life of occupationally active people, aged 45-60, living in the Polish industrial region (Silesian agglomeration). Medycyna Pracy 62(5), 455-463. [in Polish]

13. Grochans E. (2012). The impact of environmental and genetic factors on the prevalence of anxiety disorders and the quality of life in postmenopausal women. Szczecin: Wydawnictwo PUM. [in Polish]

14. Czarnecka-Iwańczuk M., Stanisławska-Kubiak M., Mojs E., Wilczak M., Samborski W. (2012). Menopause symptoms versus life satisfaction and self-esteem among women. Przeglad Menopauzalny 6, 468-473. DOI: 10.5114/ pm.2012.32539. [in Polish]
15. Grzanka-Tykwińska A., Rzepka A., Porzych K., Kusza K., Kędziora-Kornatowska K. (2012). The quality of life of patients over 60 including demographic and enviromental factors. Medical and Biological Sciences 26, 119-123.

16. Pacian A., Kulik T.B., Chruściel P., Mazurek-Sitarz M., Sitarz K., Derewiecki T. (2014). Quality of life and risk of depression among elderly people. Hygeia Public Health 49, 820-824. [in Polish]

17. Mroczek B., Wróblewska I., Jamrocha K., Jurczak A., Kurpas D. (2014). Assessment of quality of life in menopausal women. Family Medicine E Primary Care Review 16, 136137. [in Polish]

18. Janicka K. (2014). Quality of life of women in middle and late adulthood. Acta Universitatis Lodziensis, Folia Psychologica 1, 67-83. DOI: article-dlf42e2d-5c9d-40da-bd458a9blb522207. [in Polish]

19. Bojar I., Witczak M., Stępniak A., Łyszcz R., Raczkiewicz D., Humeniuk E. (2013). Cognitive functions measured with a battery of CNS VS tests and the subjective assessment of memory, concentration impairment and reduction in the quality of life in women after menopause. Przeglad Menopauzalny 5, 371-377. DOI: article-4e9lee55-8e39-46479724-c9f9ce33f4ec. [in Polish]

20. Stachoń A.J. (2013). Selected climacteric symptoms depending on the climacteric phase and type of menopause. Przeglad Menopauzalny 4, 315-320. DOI: article-dlf42e2d5c9d-40da-bd45-8a9blb522207. [in Polish]

21. Humańska M.A., Kędziora-Kornatowska K. (2009). Correlation among intensification of depressive states and quality of life in the elderly. Psychogeriatria Polska 6, 15-22. [in Polish]

22. Brown J., Bowling A., Flynn T.N. (2004). Models of quality of life: A taxonomy and systematic review of the literature. Report commissioned by European Forum on Population Ageing Research/Quality Life: University of Sheffield.

23. Rejeski W.J., Mihalko S.L. (2001). Physical activity and quality of life in older adults. Journals of Gerontology: Biological Sciences and Medicine Sciences 56, 23-35.

24. Teoman N., Ozcan A., Acar B. (2004). The effect of exercise on physical fitness and quality of life in postmenopausal women. Maturitas 47, 71-77.

25. Gębska-Kuczerowska A. (2002). Assessment of the relationship between activity and health status in elderly. Przegląd Epidemiologiczny 56, 471-477. [in Polish]

26. Grzegorczyk J., Kwolek A., Bazarnik K., Szeliga E., Wolan A. (2007). Quality of life of nursing home residents and senior mature students. Przegląd Medyczny Uniwersytetu Rzeszowskiego 3, 225-233. [in Polish]

27. Marchewka A., Jungiewicz M. (2008). Physical activity in early years of life versus quality of life in old age. Gerontologia Polska 16, 127-130. [in Polish]

28. Guszkowska M. (2012). The relation between physical activity, mood and life satisfaction in the case of women in their late adulthood. In J. Nowocień, K. Zuchora (eds.), Physical and social activity of third age persons (pp. 217-227). Warszawa: AWF. [in Polish]

29. Ciechanowicz A., Stańczak J. (2006). Attention and perceptiveness test. A handbook. Warszawa: Pracownia Testów Psychologicznych. [in Polish]

30. Goryńska E. (2005). The UMACL Mood Adjective Checklist by G. Matthews, A.G. Chamberlain and D.M. Jones. A handbook. Warszawa: Pracownia Testów Psychologicznych. [in Polish] 
31. Grodzicki T., Kocemba J., Skalska A. (2006). Geriatrics with elements of gerontology. Gdańsk: Via Medica. [in Polish]

32. Bryła M., Burzyńska M., Maniecka-Bryła I. (2013). Self-rated quality of life of city-dwelling elderly people benefitting from social help: Results of a cross-sectional study. Health and Quality of Life Outcomes 11, 181. DOI: 10.1186/14777525-11-181.

33. Lin P-S., Hsief Ch-Ch., Cheng H-S., Tseng T-J., Su S-Ch. (2016). Association between physical fitness and successful aging in Taiwanese older adults. PLoS ONE 11(3), e0150389. DOI: 10.1371/journal.pone.0150389.

34. Sławińska T., Posłuszny P., Rożek K. (2013). The relationships between physical fitness and quality of life in adults and the elderly. Human Movement 14, 200-204. DOI: 10.2478/humo-2013-0023.

Submitted: October 13, 2016

Accepted: November 8, 2016 